\title{
The influence of context on ayahuasca experiences: An analysis of experience reports
}

\author{
AVERY SAPOZNIKOW ${ }^{1}$, ZACHARY WALSH $^{1}$, KENNETH W. TUPPER ${ }^{2}$, EARTH EROWID ${ }^{3}$ and FIRE EROWID ${ }^{3}$ \\ ${ }^{1}$ Department of Psychology, University of British Columbia, Okanagan, Kelowna, Canada \\ ${ }^{2}$ School of Population and Public Health, University of British Columbia, Vancouver, BC, Canada \\ ${ }^{3}$ Erowid Center, Grass Valley, CA, USA
}

(Received: May 1, 2019; accepted: October 25, 2019)

\begin{abstract}
Background and aims: Ayahuasca is a psychedelic decoction prepared from two (or more) plants containing monoamine oxidase inhibitors, $N, N$-dimethyltryptamine, and other chemicals. Ayahuasca has apparently been used for centuries in the Amazon basin of South America, and in recent years has increasingly been used internationally in diverse contexts. This study aims to elucidate differences between cross-cultural ceremonial and psychonautic contexts of ayahuasca use. Methods: This study systematically examines subjective differences across contexts for contemporary ayahuasca-drinking practices. User reports of ayahuasca experiences were subjected to textual analysis to compare use in cross-cultural ceremonial contexts that attempt to include elements of traditional Amazonian practices, with psychonautic use that does not formally integrate traditional ceremonial aspects. The experience reports were collected from an online database. Results: The use of ayahuasca in a cross-cultural ceremonial context is associated with prominence of affective and motivational features, whereas psychonautic use was associated with an emphasis on cognitive processes. Conclusions: The beneficial effects of ayahuasca may operate via affective processing and integration and as such, cross-cultural ceremonial use may have advantages relative to psychonautic use. Findings are considered in light of the importance of context on experiences with ayahuasca and other psychedelic substances.
\end{abstract}

Keywords: ayahuasca, psychedelics, context, setting, experiences, textual analysis

\section{INTRODUCTION}

Ayahuasca is a psychoactive decoction that produces cognitive shifts, emotional lability, and visionary experiences, and has a longstanding history of use in the Amazon basin region of South America (Grob et al., 1996; Rätsch, 2005). Traditional ayahuasca is made from the stalk of the vine Banisteriopsis caapi, a source of monoamine oxidase inhibitors (MAOIs), and typically the leaves of the Psychotria viridis shrub, a source of $N, N$-dimethyltryptamine (DMT). The sources and concentrations of MAOIs and DMT may vary based on phytogenetics, growing conditions, and tradition. Diverse botanical admixture plants may also be included in some ayahuasca brews. The combination of both an MAOI and DMT is required to produce the psychedelic effects, which result from MAOI inhibiting the metabolism of orally ingested DMT (McKenna, Towers, \& Abbott, 1984; Riba et al., 2003). The psychoactive effects of DMT are comparable to those of other psychedelics that strongly affect the central nervous system (Hofmann, Ratsch, \& Schultes, 1992; Pierce \& Peroutka, 1989; Riba et al., 2003; Smith, Canton, Barrett, \& Sanders-Bush, 1998; Waldmeier \& Maître, 1977), and include profound changes in perception, affect, and cognition (Shanon, 2002) for the duration of the effects of the substance. The traditional indigenous Amazonian uses of ayahuasca involve an array of ceremonial practices (McKenna, 2006). In addition to these traditional indigenous modes of use, in the 20th century, new religious movements in Brazil incorporated ayahuasca as a sacrament into their rituals. Recent decades have witnessed the internationalization, or worldwide spread, of these kinds of ayahuasca-drinking practices, as well as novel kinds of use in contexts that diverge substantially from Amazonian traditions (Tupper, 2009).

Contemporary ayahuasca drinking can be broadly characterized by four categories: (a) Amazonian use that includes traditional or indigenous-style ceremonial elements and is directed by an expert leader (e.g., ayahuasquero, curandero, or shaman; Labate \& Cavnar, 2014); (b) formalized use in predominantly South American religious organizations, such as the Santo Daime and União do Vegetal, with novel rituals for ayahuasca consumption developed since the mid-20th century (Coomber \& South, 2004; Hofmann et al., 1992; Labate, Rose, \& Dos Santos, 2009); (c) less-formalized ceremonial uses involving diverse practices that range from

* Corresponding author: Avery Sapoznikow, BSc (Hons.), Department of Psychology, University of British Columbia Okanagan, 43 Kingsland Villas, Calgary, $\mathrm{AB} \mathrm{T} 2 \mathrm{~V}$ 5J9, Canada; Phone: +1 403630 6680; E-mail: asapoznikow@gmail.com

This is an open-access article distributed under the terms of the Creative Commons Attribution-NonCommercial 4.0 International License, which permits unrestricted use, distribution, and reproduction in any medium for non-commercial purposes, provided the original author and source are credited, a link to the CC License is provided, and changes - if any - are indicated. 
attempts to reproduce traditional Amazonian practices and constituents of admixtures, to modernized ceremonial practices that may incorporate popular music; (d) non-ceremonial use in which ayahuasca-like mixtures - sometimes referred to as pharmahuasca - are consumed individually for selfexploration (Tupper, 2009). The latter two categories, which we provisionally label as cross-cultural ceremonial and psychonautic respectively, are prominent modes of use outside of South America and are the focus of this study.

The internationalization of ayahuasca has been driven in part by the putative salutary effects of the brew, primarily for mental health and well-being. Indeed, a small but growing body of research suggests associations between ayahuasca use and reduced psychopathology and enhanced well-being (Barbosa, Giglio, \& Dalgalarrondo, 2005; Grob et al., 1996; Palhano-Fontes et al., 2019; Sanches et al., 2016; Thomas, Lucas, Capler, Tupper, \& Martin, 2013). However, research on the potential health effects of ayahuasca has focused almost exclusively on use of ayahuasca in ceremonial contexts related to formal ayahuasca religions. As such, the extent to which benefits may be expected to extend to the increasingly diverse contexts for contemporary ayahuasca drinking is unclear. In particular, the consequences of psychonautic use, which typically involve privately acquired plant materials for independent home preparation and ingestion, remain largely unexamined (Halpern \& Pope, 2001; Ott, 1994).

Context of use, or set and setting, has been identified as an important determinant of the nature of user experiences with psychedelic substances (Zinberg, 1984), with set referring generally to individual attitudes, expectations, and mood going into the psychedelic experience, and setting pertaining to the environment in which the experience occurs. Context may be a particularly important influence in responses to psychedelics (Leary, Metzner, \& Alpert, 1964; Studerus, Gamma, Kometer, \& Vollenwieder, 2012; Talin \& Sanabria, 2017), as reflected by the attention afforded to ritual steps and elements among longstanding cultural traditions of psychedelic plant use, exemplified by the incorporation of specific music and dance in the Huichol peyote ceremony and the singing of icaros in Shipibo ayahuasca ceremonies (Schultes, Hoffman, \& Rätsch, 2001). Indeed, some of the discrepant findings of early psychedelic research have been proposed to reflect differences in set and setting, and the contemporary renaissance of interest in psychedelic therapies has led to a resurgence of attention to the influence of context on psychedelic experiences and their outcomes (Hartogsohn, 2016; Tupper, Wood, Yensen, \& Johnson, 2015).

Edited databases of information, such as Erowid, as well as online fora and web-based data sets that are focused on the effects of psychoactive drugs, are increasingly used by researchers as a resource for examining the subjective effects of substances such as ayahuasca that have a relatively low prevalence of use (e.g., Hearne \& Van Hout, 2016; Sanz \& Tagliazucchi, 2018; Swogger et al., 2015). To the extent that these "experience reports" include information relevant to context, they allow for a cross-context comparison of the subjective effects of psychoactive drugs of interest. In this study, we use linguistic analysis of published texts to identify domains of experience related to reports of ayahuasca experiences and examine differences in the relative prevalence of these domains as a function of crosscultural ceremonial versus psychonautic contexts for use.

\section{METHODS}

\section{Participants}

The sample for this study comprised archival reports collected from Erowid.org (Erowid, 2017), a non-profit website dedicated to information on psychoactive substances, which publishes reports of user experiences known as "experience reports." Erowid and Erowid (2006) selected and edited the submitted experience reports according to their guidelines for quality and publication. Several prior studies have drawn data from these reports (e.g., Spaderna, Addy, \& D'Souza, 2013; Swogger et al., 2015). All published ayahuasca experience reports as of January 30, 2016 $(n=203)$ were downloaded from the website for consideration of analysis. All reports' content was screened to exclude reports involving concurrent use of additional psychoactive substances such as cannabis (the exception was tobacco, which is commonly used concurrently with ayahuasca in traditional Amazonian ritual practices); reports that lack content relevant to an experience of drinking ayahuasca (e.g., an individual discussing events not directly related to the ayahuasca experience), recipes, or guidance on brewing ayahuasca; and reports of perspectives of individuals supervising another individual's ayahuasca experience (i.e., not directly autobiographical reports). Based on these criteria, we removed 50 reports, leaving 153 reports matching inclusion criteria.

The reports were classified as "psychonautic" versus "cross-cultural ceremonial" based on several criteria: (a) location (personal residence vs. ceremonial space), (b) presence of expert guide, and (c) procedure of brew preparation and ingestion (i.e., self-made tea vs. a shamanically made and administered brew). Taking these criteria into account, the reports were read individually for eligibility in the study. Any reports of one experience split into multiple published reports were considered one report. Reports involving atypical circumstances, such as drinking ayahuasca during a music festival, were classified as psychonautic use. All reports contained sufficient detail to discern relevance to the three criteria and the most suitable category. Based on these criteria, 58 (38\%) of the included reports described use in a cross-cultural ceremonial context and $95(62 \%)$ described experiences in psychonautic contexts.

\section{Analysis}

Quantitative linguistic analysis of first-hand autobiographical texts is a data-reducing process that involves analysis of texts to identify the relative prominence of predefined categories of interest. We used the Linguistic Inquiry and Word Count software (LIWC; Pennebaker, Boyd, Jordan, \& Blackburn, 2015; Tausczik \& Pennebaker, 2010), which outputs the proportions of psychologically meaningful information into 41 predetermined categories designed to 
capture temporal, emotional, and cognitive processes. For example, the phrase "I was seeing the colors shift and bend and twist in front of me" would increase the proportions of the domains Perception \& Relativity along with the output domains for personal pronouns, verbs, etc. The phrase "It made me feel genuine sadness and fear; I thought I was lost in the dark spiral for eternity" would increase the proportions of the domains Affective Processes and Cognitive Processes. Based on previous research using LIWC, we constrained our consideration of categories to those that produced a mean output of $2 \%$ or greater (Beukeboom, Tanis, \& Vermeulen, 2012; Carey et al., 2015; Cariola, 2014; Czechowski, Miranda, \& Sylvestre, 2016; Hill, Ford, \& Farreras, 2015; Isaac, Chertoff, Lee, \& Carnes, 2011), indicating that at least $2 \%$ of the word content of the experience report loaded on the domain. Reports were edited manually based on the LIWC transcript protocol for non-fluencies, improper punctuation, and numerals. Furthermore, information pertaining to brew preparation or other elements not directly related to the psychedelic experience itself was removed to maintain consistency in analyzing content purely descriptive of the experiences. We conducted principal components analysis (PCA) of the domains identified using LIWC to explore the extent to which these categories could be reduced to a more parsimonious number of factors. The factor loading scores, reported in Table 1, are calculated using PCA and speak to the magnitude and direction of the relationship between the individual domains and the three different factors identified. Negative factor loading scores indicate a negative relationship between the individual domain and the factor. Potential scores range from -1 to 1 , with 0 indicating a lack of a relationship. Factors were then compared across contexts using multivariate analysis of variance (MANOVA).

\section{Ethics}

Due to the archival nature of this study, a formal ethics review was not required by our institution. Once users submit their articles to the Erowid Center for publication, the reports undergo Erowid Center's editorial procedures (Erowid \& Erowid, 2006) and are published in the Erowid Experience Vaults (Erowid, 2017) under the copyright of
Erowid. Individuals who submit their experience reports forfeit all rights to their report. After being granted permission to analyze the ayahuasca experiences hosted on the website, we began our analysis procedures. The authors have acknowledged the work of all individuals who have contributed to this study and report no conflicts of interest.

\section{RESULTS}

The LIWC analysis produced eight categories based on a $2 \%$ minimum cut-off (Table 1). PCA identified three factors that retained eigenvalues greater than 1 and that each accounted for more than $15 \%$ of the total variance in our data (Table 1). Thinking [consisting of cognitive processes and insight (words describing thought and introspection), accounting for $23.74 \%$ of total variance], Feeling [consisting Affective Processes, Drives, and Social Processes (words describing emotion, motivations, and social interaction), accounting for $21.52 \%$ of total variance], and Perceiving [consisting of perception, biological processes, and relativity (words describing sensory information, bodily functions, and movement), accounting for $15.81 \%$ of total variance] together accounted for a total of $61.1 \%$ of the variance. A MANOVA testing differences between psychonautic and cross-cultural ceremonial context on the extracted factors identified a significant multivariate main effect, Wilks' $\lambda=0.83, \quad F(3,149)=10.25, \quad p<.001$, $\eta^{2}=0.17$, and follow-up $t$-tests (Figure 1) identified differences on the Thinking factor, $F(1,151)=7.75, p<.01$, $\eta^{2}=0.04$, indicating higher scores in the psychonautic relative to cross-cultural ceremonial context $(M=0.17$, $S D=1.04$ vs. $M=-0.28, S D=0.86)$. The cross-cultural ceremonial context produced higher scores on the Motivation/Affective $\quad\left[F(1, \quad 151)=21.04, \quad p<.001, \quad \eta^{2}=\right.$ $0.122 ; M=0.45, S D=0.89$ vs. $M=-0.27, S D=0.97]$. No differences were identified on scores on the Perceiving Factor $\left[F(1,151)=0.02, p=.89, \eta^{2}=0.00 ; M=-0.01\right.$, $S D=0.85$ vs. $M=0.01, S D=1.08]$.

Supplementary analyses examined differences on each of the eight LIWC domains, indicating a multivariate effect, Wilks' $\lambda=0.763, F(8,144)=5.60, p<.001, \eta^{2}=0.237$. Follow-up ANOVA identified higher scores for cross-

Table 1. Mean percentage of domain content and factor loading scores

\begin{tabular}{lrcrr}
\hline Domain & Mean \% $(S D)$ & Factor 1 (Cognitive) & Factor 2 (Motivational/Affective) & Factor 3 (Perception) \\
\hline Affective processes & $4.39(1.40)$ & $\mathbf{0 . 3 3 9}$ & $\mathbf{0 . 6 9 9}$ & $\mathbf{0 . 3 7 4}$ \\
Cognitive processes & $11.99(2.54)$ & $\mathbf{0 . 8 8 9}$ & -0.048 & -0.127 \\
Insight & $3.34(1.16)$ & $\mathbf{0 . 7 8 3}$ & -0.115 & 0.296 \\
Perception & $4.57(1.19)$ & 0.017 & -0.113 & $\mathbf{0 . 5 3 8}$ \\
Biological processes & $3.35(1.24)$ & -0.128 & 0.142 & $\mathbf{0 . 7 4 6}$ \\
Drives & $5.26(1.28)$ & -0.107 & $\mathbf{0 . 8 5 1}$ & 0.019 \\
Relativity & $15.18(2.31)$ & -0.566 & -0.095 & $\mathbf{0 . 3 1 8}$ \\
Social processes & $5.07(2.48)$ & -0.130 & $\mathbf{0 . 6 8 4}$ & -0.281 \\
\hline
\end{tabular}

Note. Bold values indicate highly loading domains on the extracted factors. This table represents the mean percentage of total word content that each domain held on our data set as well as the corresponding factor loading scores from the principal components analysis. "Mean \%" column refers to the average percent of word content across all experiences reports from each domain. Factor loading scores indicate the magnitude and direction of the relationship (i.e., the larger the number, the greater the strength of the relationship and negative values indicate a negative relationship between the domain and factor). 
cultural ceremonial contexts for Affective Processes, Drives, and Social Processes, whereas psychonautic contexts produced higher scores for Cognitive Processes and Insight (Table 2).

\section{DISCUSSION}

We identified differences between reports of psychonautic and cross-cultural ceremonial contexts for ayahuasca drinking such that descriptions of cross-cultural ceremonial uses were characterized by a higher proportion of affective (mood-related) and motivational content as well as a lower proportion of cognitive processes. Broadly stated, cross-

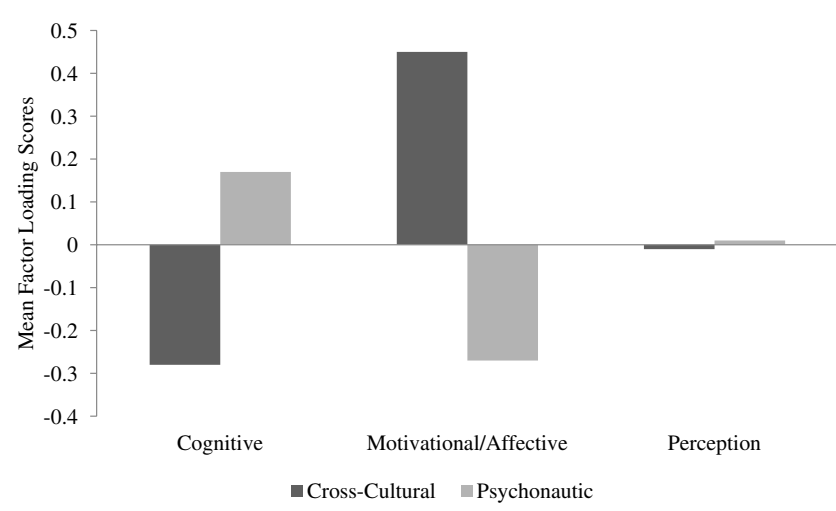

Figure 1. Differences between cross-cultural and psychonautic experiences on extracted factors. Standard deviations: Cross cultural: 0.86 (Cognitive); 0.89 (Motivational/Affective); 0.85

(Perceiving). Psychonautic: 1.04 (Cognitive); 0.97 (Motivational/ Affective); 1.08 (Perceiving). A bar graph represents the differences between cross-cultural and psychonautic ayahuasca use in terms of factor loading scores for each of the extracted factors. This graph details the extent to which each factor is associated with either type of ayahuasca use. Significant differences found for the Cognitive and Motivational/Affective factors cultural ceremonial contexts appear to be associated with relatively more feeling and less thinking. These findings are based on the assumptions that through linguistic analysis, themes associated with affective and cognitive processes are directly related to the set, and perceptual themes are related to setting. Although both set and setting are correlated, the distinction between cognition and emotion versus perception allows for a comparison between the two aspects of set to be made.

These findings have the potential to inform future research and practice related to the therapeutic uses of ayahuasca. Specifically, to the extent that the salutary effects of ayahuasca, and psychedelic psychotherapy more broadly, operate via the facilitation of affective processing and integration (Loizaga-Velder, 2014; Mithoefer, Grob, \& Brewerton, 2016), these conclusions suggest that, relative to a psychonautic context, the cross-cultural ceremonial context may have salutary advantages. Indeed, ceremonial use of ayahuasca has been associated with reductions in symptoms of depression, anxiety, and trauma (Dos Santos et al., 2016; Palhano-Fontes et al., 2019; Sanches et al., 2016; Talin \& Sanabria, 2017); each of which has been proposed to include dysregulation of emotions and motivation in their respective etiologies (American Psychiatric Association, 2013). The preponderance of affective content may be particularly salient in the case of trauma-related psychopathologies, such as post-traumatic stress disorder, in which the reprocessing of affectively laden material has been proposed to play a central therapeutic role (Monson et al., 2006; Resick, Nishith, Weaver, Millie, \& Feurer, 2010). Future research may confirm the therapeutic advantages of the cross-cultural ceremonial context, as it borrows elements from long standing therapeutic technologies; ayahuasca has traditionally been used in the Amazon basin for the treatment of psychological (or psychospiritual) maladies, and practitioners of ayahuasca-based therapies have developed effective and sophisticated approaches to maximizing the therapeutic impact of ayahuasca.

Table 2. Bivariate follow-up ANOVAs for the significant MANOVA of LIWC domains

\begin{tabular}{|c|c|c|c|c|}
\hline Domain & Setting & Mean $(S D)$ & $F$ value & $p$ value \\
\hline \multirow[t]{2}{*}{ Affective processes } & Psychonautic & $4.14(1.24)$ & 8.41 & .004 \\
\hline & Cross-cultural & $4.80(1.55)$ & & \\
\hline \multirow[t]{2}{*}{ Cognitive processes } & Psychonautic & $12.51(2.72)$ & 11.08 & .001 \\
\hline & Cross-cultural & $11.15(1.95)$ & & \\
\hline \multirow[t]{2}{*}{ Insight } & Psychonautic & $3.55(1.26)$ & 8.29 & .005 \\
\hline & Cross-cultural & $3.01(0.87)$ & & \\
\hline \multirow[t]{2}{*}{ Perception } & Psychonautic & $4.50(1.18)$ & 0.90 & .344 \\
\hline & Cross-cultural & $4.69(1.22)$ & & \\
\hline \multirow[t]{2}{*}{ Biological processes } & Psychonautic & $3.37(1.30)$ & 0.03 & .866 \\
\hline & Cross-cultural & $3.33(1.14)$ & & \\
\hline \multirow[t]{2}{*}{ Drives } & Psychonautic & $5.03(1.32)$ & 8.48 & .004 \\
\hline & Cross-cultural & $5.63(1.12)$ & & \\
\hline \multirow[t]{2}{*}{ Relativity } & Psychonautic & $15.08(2.34)$ & 0.48 & .490 \\
\hline & Cross-cultural & $15.35(2.27)$ & & \\
\hline \multirow[t]{2}{*}{ Social processes } & Psychonautic & $4.40(2.34)$ & 20.57 & $<.001$ \\
\hline & Cross-cultural & $6.17(2.33)$ & & \\
\hline
\end{tabular}

Note. Bold values represent significant results for Affective, Cognitive, and Social Processes, Insight, and Drives. SD: standard deviation; ANOVA: analysis of variance; MANOVA: multivariate analysis of variance; LIWC: Linguistic Inquiry and Word Count. 
On the contrary, our findings tentatively suggest that psychonautic use of ayahuasca may not confer the same emotional benefits that are associated with cross-cultural ceremonial ayahuasca drinking, which tends to involve formalized drinking practices and guidance, and as such, may allow for more emotionally focused experiences through this guidance. Given the expansion of psychedelic drug use for diverse purposes (Fadiman, 2011), and the relative dearth of guidance regarding optimization of psychedelic use for specified ends, preliminary findings such as these may be informative. In addition, it is important to note that it is the conflict between our results and recent literature suggesting that ayahuasca modulates cognitive dimensions through mindfulness and increases in divergent versus convergent thinking (Kuypers et al., 2016; Sampedro et al., 2017; Soler et al., 2016, 2018; Uthang et al., 2018). This conflict suggests that a dynamic interaction occurs involving both cognitive and affective processes, which in turn impacts the user.

Our conclusions are limited by the nature of the available textual material we analyzed. Specifically, the reliability and validity of the reports are unknown, and it is possible that they may include experiences that are not directly the result of ayahuasca, and may be flawed or skewed by poor recollection of the experiences by the writers. Furthermore, due to reliance on anonymous authors, there is no way to establish the accuracy of the representation of the ayahuasca experiences. When considering intentions and/or goals for ayahuasca use versus those in psychotherapy, the goals one may strive for are far less defined when taking ayahuasca than a formal treatment setting. Therefore, potential positive or negative impact on mental state is more difficult to prove. In addition, the motivations of the individuals who submitted the analyzed experience reports vary and therefore some reports may be less impactful than described. This study considers less-formalized ceremonial use and nonceremonial use for analysis due to the lack of indigenous and religious use reported in the collected experience reports. This limits the ability to draw conclusions regarding formal ceremonial ayahuasca use in indigenous and religious contexts. This study is limited by the manual editing of all reports. All reports were edited by the same individual to match the analysis software's textual requirements (e.g., sentences containing numerical symbols such as, "I drank the ayahuasca 4 hours ago" would be edited to "I drank the ayahuasca four hours ago") and information that was irrelevant to the analysis of the experience itself, such as recipes, prologues, and epilogues to experiences, etc., was removed. The intention of this practice was to isolate the ayahuasca experience itself from the entire report to allow for an analysis of only the experiences; however, there is a possibility that some relevant information was removed. Furthermore, the selection/editing criteria applied by the editors of Erowid significantly differ from our editing process. Therefore, some of the excluded reports may have influenced our results. It should also be noted that the results and interpretations of this study may be negatively skewed because all writers live in North America. We have many different cultural and ethnic differences, which influence our thinking with regard to ayahuasca, which likely differ to that of the traditional indigenous peoples of the Amazon. These limitations are shared with other research that has drawn from experience reports, and it is our belief that despite the clear limitations of these data, they nonetheless contain information that is potentially valuable, particularly in areas where empirical research is currently scant and subject to substantial barriers.

Beyond the limitations, inherent on reliance on experience reports are factors that covary with context and thus complicate inferences related to locus of effects. At the level of the brew itself, it is possible that the ayahuasca consumed in the cross-cultural ceremonial context may differ in content and production style, and as such the observed differences may be attributable to differences in the ayahuasca decoctions ingested rather than to the context per se. Differences may also be attributable to the set that is influenced by the chosen context in which the ayahuasca will be used. In addition, demographic factors such as age and socioeconomic status may also be pertinent with regard to the chosen setting for users; ceremonial contexts may be more likely to involve a financial commitment and thus may limit the ability of younger or less wealthy individuals to partake in traditional ayahuasca ceremonies. Or there might be other underlying differences in personality, diction, or style of experience reporting between psychonauts who decide to make and/or use homemade, self-administered ayahuasca, and those who use ayahuasca in cross-cultural ceremonial contexts. Moreover, the extent to which apparent contextual differences reflect set, setting, or both elements is difficult to parse as differences in setting may serve as a marker for differences in set; the intention and attitudes of respondents who sought cross-cultural ceremonial settings may have differed in meaningful ways from the set of those who drank ayahuasca in psychonautic settings. The design of this study does not allow for the careful parsing of the extent to which differences in the content of ayahuasca experiences reflect the pharmacology of the brew, the set of participants, and the setting of the experiences, and these factors and others likely interact in complex ways. Interestingly, recent studies that have administered ayahuasca in a clinical setting have reported anti-depressant effects (Palhano-Fontes et al., 2019; Sanches et al., 2016), which suggest potential for salutary mental health effects outside of a ceremonial context. Future clinical research is required to more definitively address the many interesting and consequential gaps in our understanding of psychedelic medicines. Pending such investigations, and with the above limitations in mind, this study may help to provide future researchers with a foundation for investigating the influence of context on the effects of ayahuasca and psychedelic medicines more generally

Acknowledgements: The authors would like to thank Matthew Baggott, $\mathrm{PhD}$, for contributing in editing of the manuscript prior to submission.

Conflict of interest: The authors declare no conflict of interest. 


\section{REFERENCES}

American Psychiatric Association. (2013). Diagnostic and statistical manual of mental disorders (5th ed.). Arlington, VA: American Psychiatric Association.

Barbosa, P. C., Giglio, J. S., \& Dalgalarrondo, P. (2005). Altered states of consciousness and short-term psychological aftereffects induced by the first time ritual use of ayahuasca in an urban context in Brazil. Journal of Psychoactive Drugs, 37(2), 193-201. doi:10.1080/02791072.2005.10399801

Beukeboom, C. J., Tanis, M., \& Vermeulen, I. E. (2012). The language of extraversion: Extraverted people talk more abstractly, introverts are more concrete. Journal of Language and Social Psychology, 32(2), 191-201. doi:10.1177/0261927X12460844

Carey, A. L., Brucks, M. S., Küfner, A. C., Holtzman, N. S., Große Deters, F., Back, M. D., Donnellan, M. B., Pennebaker, J. W., \& Mehl, M. R. (2015). Narcissism and the use of personal pronouns revisted. Journal of Personality \& Social Psychology, 109(3), e1-e15. doi:10.1037/pspp0000029

Cariola, L. A. (2014). Lexical tendencies of high and low barrier personalities in narratives of everyday and dream memories. Imagination, Cognition, and Personality, 34(2), 133-161. doi:10.2190/IC.34.2.d

Coomber, R., \& South, N. (Eds.). (2004). Drug use and cultural contexts 'Beyond the West': Tradition, change and postcolonialism. London, UK: Free Association Books.

Czechowski, K., Miranda, D., \& Sylvestre, J. (2016). Like a rolling stone: A mixed-methods approach to linguistic analysis of Bob Dylan's lyrics. Psychology of Aesthetics, Creativity, and the Arts, 10(1), 99-113. doi:10.1037/aca0000045

Dos Santos, R. G., Osório, F. L., Crippa, J. A. S., Riba, J., Zuardi, A. W., \& Hallak, J. E. C. (2016). Antidepressive, anxiolytic, and antiaddictive effects of ayahuasca, psilocybin and lysergic acid diethylamide (LSD): A systematic review of clinical trials published in the last 25 years. Therapeutic Advances in Psychopharmacology, 6(3), 193-213. doi:10.1177/204512 5316638008

Erowid, E. (2017). Erowid experience vaults. Retrieved from http://www.erowid.org/exp

Erowid, E., \& Erowid, F. (2006). The value of experience. Erowid Extracts, 10, 14-19. Retrieved from https://erowid.org/ experiences/exp_info3.shtml

Fadiman, J. (2011). The psychedelic explorer's guide: Safe, therapeutic, and sacred journeys. Rochester, VT: Park Street Press.

Grob, C. S., McKenna, D. J., Callaway, J. C., Brito, G. S., Neves, E. S., Oberlaender, G., Saide, O. L., Labigalini, E., Tacla, C., Miranda, C. T., Strassman, R. J., \& Boone, K. B. (1996). Human psychopharmacology of hoasca, a plant hallucinogen used in ritual context in Brazil. Journal of Nervous and Mental Disease, 184(2), 86-94. doi:10.1097/00005053-199602000-00004

Halpern, J. H., \& Pope, H. G. (2001). Hallucinogens on the Internet: A vast new source of underground drug information. American Journal of Psychiatry, 158(3), 481-483. doi:10.1176/ appi.ajp.158.3.481

Hartogsohn, I. (2016). Set and setting, psychedelics and the placebo response: An extra-pharmacological perspective on psychophamacology. Journal of Psychopharmacology, 30(12), 1259-1267. doi:10.1177/0269881116677852

Hearne, E., \& Van Hout, M. C. (2016). "Trip-Sitting” in the black hole: A netnographic study of dissociation and indigenous harm reduction. Journal of Psychoactive Drugs, 48(4), 233-242. doi:10.1080/02791072.2016.1207827

Hill, J., Ford, W. R., \& Farreras, I. G. (2015). Real conversations with artificial intelligence: A comparison between humanhuman online conversations and human-chatbot conversations. Computers in Human Behavior, 49, 245-250. doi:10.1016/ j.chb.2015.02.026

Hofmann, A., Ratsch, C., \& Schultes, R. (1992). Plants of the Gods: Their Sacred, Healing, and Hallucinogenic Powers. Rochester, NY: Healing Arts Press.

Isaac, C., Chertoff, J., Lee, B., \& Carnes, M. (2011). Do students' and authors' genders affect evaluations? A linguistic analysis of medical student performance evaluations. Academic Medicine, 86(1), 59-66. doi:10.1097/ACM.0b013e318200561d

Kuypers, K. P., Riba, J., de la Fuente Revenga, M., Barker, S., Theunissen, E. L., \& Ramaekers, J. G. (2016). Ayahuasca enhances creative divergent thinking while decreasing conventional convergent thinking. Psychopharmacology, 233(18), 3395-3403. doi:10.1007/s00213-016-4377-8

Labate, B. C., \& Cavnar, C. (Eds.). (2014). The therapeutic use of Ayahuasca. Berlin/Heidelberg, Germany: Springer-Verlag.

Labate, B. C., Rose, I. S., \& Dos Santos, R. G. (2009). Ayahuasca religions: A comprehensive bibliography and critical essays. Santa Cruz, CA: Multidisciplinary Association for Psychedelic Studies.

Leary, T., Metzner, R., \& Alpert, R. (1964). The psychedelic experience: A manual based on the Tibetan book of the dead. New Hyde Park, NY: University Books.

Loizaga-Velder, A. (2014). Therapeutic effects of ritual ayahuasca use in the treatment of substance dependence - Qualitative results. Journal of Psychoactive Drugs, 46(1), 63-72. doi:10.1080/02791072.2013.873157

McKenna, D. J. (2006). Ayahuasca an ethnopharmacologic history. In R. Metzner (Eds.), Sacred vine of spirits: Ayahuasca (pp. 40-62). Rochester, VT: Park Street Press.

McKenna, D. J., Towers, G. H. N., \& Abbott, F. S. (1984). Monoamine oxidase inhibitors in South American hallucinogenic plants: Tryptamine and $\beta$-carboline constituents of ayahuasca. Journal of Ethnopharmacology, 10(2), 195-223. doi:10.1016/0378-8741(84)90003-5

Mithoefer, M. C., Grob, C. S., \& Brewerton, T. D. (2016). Novel psychopharmacological therapies for psychiatric disorders: Psilocybin and MDMA. The Lancet Psychiatry, 3(5), 481-488. doi:10.1016/S2215-0366(15)00576-3

Monson, C. M., Schnurr, P. P., Resick, P. A., Friedman, M. J., Young-Xu, Y., \& Stevens, S. P. (2006). Cognitive processing therapy for veterans with military-related posttraumatic stress disorder. Journal of Consulting and Clinical Psychology, 74(5), 898-907. doi:10.1037/0022-006X.74.5.898

Ott, J. (1994). Ayahuasca analogues: Pangaean entheogens. Kennewick, WA: Natural Products Company.

Palhano-Fontes, F., Barreto, D., Onias, H., Andrade, K. C., Novaes, M. M., Pessla, J. A., Mota-Rolim, S. A., Osório, F. L., Sanches, R., Dos Santos, R. G., Tófoli, L. F., de Oliveira Silveira, G., Yonamine, M., Riba, J., Santos, F. R., Silva-Junior, A. A., Alchieri, J. C., Galvão-Coelho, N. L., Lobão-Soares, B., Hallak, J. E. C., Arcoverde, E., Maiade-Oliveira, J. P., \& Araújo, D. B. (2019). Rapid antidepressant effects of the psychedelic ayahuasca in treatment-resistant depression: A randomized placebo-controlled trial. 
Psychological Medicine, 49(4), 655-663. doi:10.1017/ S0033291718001356

Pennebaker, J. W., Boyd, R. L., Jordan, K., \& Blackburn, K. (2015). The development and psychometric properties of LIWC2015. Austin, TX: University of Texas at Austin.

Pierce, P. A., \& Peroutka, S. J. (1989). Hallucinogenic drug interactions with neurotransmitter receptor binding sites in human cortex. Psychopharmacology, 97(1), 118-122. doi:10.1007/BF00443425

Rätsch, C. (2005). The Encyclopedia of psychoactive plants: Ethnopharmacology and its applications. Rochester, VT: Park Street Press.

Resick, P. A., Nishith, P., Weaver, T. L., Millie, C. A., \& Feurer, C. A. (2010). A comparison of cognitive-processing therapy with prolonged exposure and a waiting condition for the treatment of chronic posttraumatic stress disorder in female rape victims. Journal of Consulting and Clinical Psychology, 70(4), 867-879. doi:10.1037/0022-006X.70.4.867

Riba, J., Valle, M., Urbano, G., Yritia, M., Morte, A., \& Barbanoj, M. J. (2003). Human pharmacology of ayahuasca: Subjective and cardiovascular effects, monoamine metabolite excretion, and pharmacokinetics. Journal of Pharmacology, 306, 73-83. doi:10.1124/jpet.103.049882

Sampedro, F., de la Fuente Revenga, M., Valle, M., Roberto, N., Domínguez-Clavé, E., Elices, M., Luna, L. E., Crippa, J. A. S., Hallak, J. E. C., de Araujo, D. B., Friedlander, P., Barker, S. A., Álvarez, E., Soler, J., Pascual, J. C., Feilding, A., \& Riba, J. (2017). Assessing the psychedelic "After-Glow" in ayahuasca users: Post-acute neurometabolic and functional connectivity changes are associated with enhanced mindfulness capacities. International Journal of Neuropsychopharmacology, 20(9), 698-711. doi:10.1093/ijnp/pyx036

Sanches, R. F., Osório, F. L., dos Santos, R. G., Macedo, L. R. H., Maia-de-Oliveira, J. P., Wichert-Ana, L., de Araujo, D. B., Riba, J., Crippa, J. A. S., \& Hallak, J. E. (2016). Antidepressant effects of a single dose of ayahuasca in patients with recurrent depression: A SPECT study. Journal of Clinical Psychopharmacology, 36(1), 77-81. doi:10.1097/JCP.00000 00000000436

Sanz, C., \& Tagliazucchi, E. (2018). The experience elicited by hallucinogens presents the highest similarity to dreaming within a large database of psychoactive substances reports. Frontiers in Neuroscience, 12, 7. doi:10.3389/fnins.2018. 00007

Schultes, R. E., Hofmann, A., \& Rätsch, C. (2001). Plant of the gods: Their sacred, healing, and hallucinogenic powers. Rochester, VT: Healing Arts Press.

Shanon, B. (2002). The antipodes of the mind: Charting the phenomenology of the ayahuasca experience. Oxford, NY: Oxford University Press.

Smith, R., Canton, H., Barrett, R. J., \& Sanders-Bush, E. (1998). Agonist properties of $N, N$-dimethyltryptamine at serotonin 5-HT2A and 5-HT2C receptors. Pharmacology Biochemistry and Behavior, 61(3), 323-330. doi:10.1016/S0091-3057(98) 00110-5
Soler, J., Elices, M., Domínguez-Clavé, E, Pascual, J. C., Feilding, A., Navarro-Gil, M., García-Campayo, J., \& Riba, J. (2018). Four weekly ayahuasca sessions lead to increases in "Acceptance" capacities: A comparison study with a standard 8 -week mindfulness training program. Frontiers in Pharmacology, 9, 224. doi:10.3389/fphar.2018.00224

Soler, J., Elices, M., Franguesa, A., Barker, S., Friedlander, P., Feilding, A., Pascual, J. C., \& Riba, J. (2016). Exploring the therapeutic potential of ayahuasca: Acute intake increases mindfulness-related capacities. Psychopharmacology, 233(5), 823-829. doi:10.1007/s00213-015-4162-0

Spaderna, M., Addy, P. H., \& D'souza, D. C. (2013). Spicing things up: Synthetic cannabinoids. Psychopharmacology, 228(4), 525-540. doi:10.1007/s00213-013-3188-4

Studerus, E., Gamma, A., Kometer, M., \& Vollenwieder, F. X. (2012). Prediction of psilocybin response in healthy volunteers. PLoS One, 7(2), e30800. doi:10.1371/journal.pone.0030800

Swogger, M. T., Hart, E., Erowid, F., Erowid, E., Trabold, N., Yee, K., Parkhurst, K. A., Priddy, B. M., \& Walsh, Z. (2015). Experience of Kratom users: A qualitative analysis. Journal of Psychoactive Drugs, 47(5), 360-367. doi:10.1080/02791072. 2015.1096434

Talin, P., \& Sanabria, E. (2017). Ayahuasca's entwined efficacy: An ethnographic study of ritual healing from 'addiction'. The International Journal of Drug Policy, 44, 23-30. doi:10.1016/ j.drugpo.2017.02.017

Tausczik, Y. R., \& Pennebaker, J. W. (2010). The psychological meaning of words; LIWC and computerized text analysis methods. Journal of Language and Social Psychology, 29(1), 24-54. doi:10.1177/0261927X09351676

Thomas, G., Lucas, P., Capler, N. R., Tupper, K. W., \& Martin, G. (2013). Ayahuasca-assisted therapy for addiction: Results from a preliminary observational study in Canada. Current Drug Abuse Reviews, 6(1), 30-42. doi:10.2174/1573399811309 9990003

Tupper, K. W. (2009). Ayahuasca healing beyond the Amazon: The globalization of a traditional indigenous entheogenic practice. Global Networks: A Journal of Transnational Affairs, 9(1), 117-136. doi:10.1111/j.1471-0374.2009.00245.x

Tupper, K. W., Wood, E., Yensen, R., \& Johnson, M. W. (2015). Psychedelic medicine: A re-emerging therapy. Canadian Medical Association Journal, 187(14), 1054-1059. doi:10.1503/ cmaj.141124

Uthang, M. V., van Oorsouw, K., Kuypers, K. P. C., van Boxtel, M., Broers, N. J., Mason, N. L., Toennes, S. W., Riba, J., \& Ramaekers, J. G. (2018). Sub-acute and long-term effects of ayahuasca on affect and cognitive thinking style and their association with ego dissolution. Psychopharmacology, 235, 2979-2989. doi:10.1007/s00213-018-4988-3

Waldmeier, P. C., \& Maître, L. (1977). Neurochemical investigations of the interaction of $N, N$-dimethyltryptamine with the dopaminergic system in rat brain. Psychopharmacology, 52(2), 137-144. doi:10.1007/BF00439100

Zinberg, N. E. (1984). Drug, set, and setting: The basis for controlled intoxicant use. New Haven, CT: Yale University Press. 